\title{
MITF Isoforms- Insights from an RNA-Seq study
}

Kritika Kirty ${ }^{*}$ Snævar Sigurðsson, Porkell Guðjónsson, Berglind Ósk Einarsdóttir, Stefán Sigurðsson

*corresponding author, email: kritikakirty@gmail.com

The manuscript has been withdrawn because of lack of full consent from all co-authors.

Therefore, the corresponding author does not wish this work to be cited as reference for the project. If you have any questions, please contact the corresponding author. 